\title{
LUIZA, ISABEL E LEOPOLDINA: UMA HISTÓRIA DE MULHERES, NOBREZA E EDUCAÇÃO NO BRASIL IMPERIAL (1856-1864)
}

DOI: http://dx.doi.org/10.1590/2236-3459/77091

\author{
Ana Cristina B. López M. Francisco' \\ 'Universidade Católica de Petrópolis (UCP), Petrópolis/RJ, Brasil \\ Maria Celi Chaves Vasconcelos" \\ "Universidade do Estado do Rio de Janeiro (Uerj), Rio de Janeiro/RJ, Brasil
}

\section{$\cos 8$}

\begin{abstract}
Resumo
O artigo trata da atuação da condessa de Barral, Luiza Margarida Portugal de Barros, como preceptora das princesas Isabel e Leopoldina, escolhida pelo próprio Imperador, D. Pedro II, para educar suas filhas. O objetivo central é recompor aspectos da condução educacional dirigida pela condessa nos palácios de São Cristóvão e Petrópolis, especialmente, as estratégias utilizadas para ensinar e educar as duas meninas, ciente da responsabilidade que tal função implicava. A pesquisa apresenta-se como histórico-documental e utilizou, sobretudo, egodocumentos, produzidos pelas princesas e pela própria condessa, colocados em diálogo com autores que enfocam temática semelhante. Conclui-se, que a condessa exerceu forte influência na vida das princesas, desde a infância até após o casamento de ambas.

Palavras-chave: Condessa de Barral, educação de crianças nobres, Império do Brasil.
\end{abstract}

\section{LUIZA, ISABEL Y LEOPOLDINA: UNA HISTORIA DE MUJERES, NOBLEZA Y EDUCACIÓN EN BRASIL IMPERIAL (1856-1864)}

\section{Resumen}

El artículo trata de la actuación de la condesa de Barral, Luiza Margarida Portugal de Barros, como preceptora de las princesas Isabel y Leopoldina, elegida por el propio Emperador, D. Pedro II, para educar a sus hijas. El objetivo central es recomponer aspectos de la conducción educativa dirigida por la condesa en los palacios de San Cristóbal y Petrópolis, en especial, las estrategias utilizadas para enseñar y educar a las dos niñas, conscientes de la responsabilidad que dicha función implicaba. La investigación se presenta como históricodocumental y utilizó, sobre todo, egodocumentos, producidos por las princesas y por la propia condesa, colocados en diálogo con autores que enfocan temática semejante. Se concluye que la condesa ejerció una fuerte influencia en la vida de las princesas, desde la infancia hasta después del matrimonio de ambas. Palabras clave: Condesa de Barral, educación de niños nobles, Imperio de Brasil. 


\title{
LUIZA, ISABEL AND LEOPOLDINA: A HISTORY OF WOMEN, NOBILITY AND EDUCATION IN IMPERIAL BRAZIL (1856-1864)
}

\begin{abstract}
The article looks at the performance of the Countess of Barral, Luiza Margarida Portugal de Barros, as tutor of the princesses Isabel and Leopoldina, who was chosen by the Emperor himself, D. Pedro II, to educate his daughters. The article aims at recomposing aspects of the educational practice lead by the countess in the palaces of Saint Cristovão and Petropolis, especially the strategies used to teach and educate the two girls, taking into account that she aware of the responsibility that this position implied. The research bears the stamp of historical-documentary and it has used, above all, egodocuments, produced by the princesses and by the countess herself, placed in dialogue with authors who focus on similar topics. It is concluded that the countess exerted a strong influence on the life of the princesses, from childhood until after their marriage.

Keywords: Countess of Barral, Education of noble children, Empire of Brazil.
\end{abstract}

\section{LUIZA, ISABEL ET LEOPOLDINA: UNE HISTOIRE SUR FEMMES, NOBLESSE ET ÉDUCATION DANS LE BRÉSIL IMPÉRIAL (1856-1864)}

\begin{abstract}
Resumé
L'article concerne le rôle de la comtesse de Barral, Luiza Margarida Portugal de Barros, en tant que tutrice choisie par l'empereur D. Pedro II pour éduquer ses filles, les princesses Isabel et Leopoldina. Le but central est de recomposer des aspects de la conduite éducative menée par la comtesse dans les palais de SaintCristóvão et Petrópolis, en particulier les stratégies utilisées pour leur enseignement et éducation, qui était consciente de la responsabilité que cette fonction impliquait. Cette recherche se présente sous forme historique-documentaire et pour cela à utilisé des documents authentiques, egodocuments, produits par les princesses bien comme par la comtesse elle-même, lesquels ont aussi été mis en dialogue avec d'autres auterurs travaillant sur des sujets similaires. On conclut que la comtesse a exercé une forte influence dans la vie des princesses, depuis leur enfance et même après leus mariages.

Mots-clés: Comtesse de Barral, l'éducation des enfants nobles, Empire du Brésil.
\end{abstract}




\section{Introdução}

- ste artigo tem como objetivo apresentar alguns aspectos das estratégias utilizadas pela condessa de Barral para condução educacional das filhas do Imperador D. Pedro II, Isabel e Leopoldina, tendo em vista a sua escolha para o cargo de preceptora governante, ou "aia", como é chamada pelas próprias princesas.

Num primeiro momento, são descritas as tratativas de contratação da, então, viscondessa de Barral para atuar como preceptora das duas meninas nobres que poderiam, um dia, vir a governar o Brasil, demonstrando a importância que essa incumbência tinha para o Imperador, tornando-se um assunto de estado e sendo planejado com muitos detalhes acordados entre ambas as partes, o monarca contratante e a viscondessa preceptora.

A seguir, após a chegada da preceptora ao Rio de Janeiro, já elevada à condição de condessa de Barral, o estudo descreve aspectos da relação entre a aia e suas discípulas, demonstrando a enorme influência que Luiza exercerá sobre Isabel e Leopoldina, muito além da simples supervisão da educação formal de ambas. Tal influência já se verifica desde os primeiros anos do cotidiano de ensino das princesas sob a supervisão da condessa, nos Paços Imperiais, com notadas evidências da implementação de hábitos e de estudos somente do que a condessa julgava apropriado para a educação das futuras soberanas.

Para a recomposição dos vestígios que permaneceram dessa longeva relação entre Luiza, Isabel e Leopoldina, a pesquisa se caracteriza como essencialmente documental, cujas fontes utilizadas não se encontram em um único acervo, mas estão "espalhadas" em distintos arquivos, contendo informações da vida e da trajetória da condessa na França e no Brasil, cartas e egodocumentos produzidos pela própria e pelas princesas, e cartas e registros de contemporâneos sobre elas.

Entre 1856 e 1864, no período em que foi preceptora das princesas Isabel e Leopoldina, a condessa tornou-se um parâmetro do ideal de governess, dedicada à educação das principais personagens femininas que iriam atuar e conduzir as circunstâncias sociais, econômicas e políticas do devir na história do Brasil. Ora, tal missão não poderia ser confiada a alguém que não fosse considerada à altura da responsabilidade que este cargo implicava e que, provavelmente, deve ter sido testada por diversas vezes e por pessoas e instituições (com seus interesses distintos), tendo superado a todos e a tudo que estivesse em seu caminho, haja vista a longevidade de sua permanência na condução da educação das princesas.

Assim, o enfoque da pesquisa apresentada neste artigo é a condessa de Barral como preceptora das princesas imperiais, suas escolhas pedagógicas e suas concepções sobre a "boa" educação no oitocentos, especialmente, aquela que seria adequada a mulheres, cujo destino poderia ser o governo de uma nação.

O estudo é finalizado, buscando evidenciar como a condessa de Barral tornou-se a única preceptora ao longo de toda a infância e a adolescência das princesas brasileiras, ocupando o mais alto cargo na educação das futuras soberanas e tornando sua postura educacional, suas escolhas e seu comportamento, exemplos da "boa educação" feminina, aspirada pelas elites brasileiras, e sua influência sobre as princesas estendendo-se até após o casamento de ambas. Todavia, o artigo também leva à reflexão sobre o quanto as 
decisões da condessa foram acertadas ou não, naquilo que se esperava para a educação de alguém que um dia iria governar a nação.

\section{Em busca de uma preceptora: "A aia para as princesas é cada vez mais precisa"1}

A preceptora escolhida para dirigir a educação das princesas Isabel e Leopoldina, durante toda a formação das presuntivas herdeiras do Trono do Brasil, foi uma mulher brasileira, nascida em Salvador, na Bahia, em 13 de abril de 1816, e batizada como Luiza Margarida Portugal de Barros.

Luiza era filha de um dos grandes homens do Império brasileiro, o visconde de Pedra Branca, representante da nobreza reinante nas Províncias e senhor de engenhos de açúcar localizados no recôncavo baiano. Tornando-se a única filha legítima ${ }^{2}$ do visconde, após a morte do irmão e da mãe, Luiza teve uma educação diferenciada, acompanhando o pai em muitas viagens diplomáticas, conhecendo vários países da Europa, embora grande parte de sua infância e quase toda a juventude fossem passadas na França, o que contribuiu, consideravelmente, para seu alto grau de cultura, destacando-a acima da educação feminina brasileira da época. (FRANCISCO, 2017; DEL PRIORE, 2008; MATOS, 1976; PINHO, 1959).

O título de viscondessa e, posteriormente, condessa de Barral, provinham de seu casamento com Jean Horace Joseph Eugêne, visconde de Barral, marquês de Montferrat e marquês De La Batîe D'Arvillars, nascido na França, em 19 de outubro de 1812, marido que ela mesma escolheu quando já tinha 21 anos, a despeito do pretendente acertado por seu pai, o qual nada pode fazer a não ser consentir com a decisão da filha. (MONTEIRO, 1962). Após o casamento, ela e o marido viveram a maior parte do tempo na França, convivendo com a aristocracia e a Corte daquele país.

O vínculo da viscondessa de Barral com a França foi decisivo para sua escolha pelo Imperador D. Pedro II como "aia" de suas filhas. Em 1843, a princesa Francisca de Bragança, irmã do jovem Imperador do Brasil, D. Pedro II, casa, no Rio de Janeiro, com o príncipe de Joinville, terceiro filho do rei da França, Luiz Felipe de Orléans. Nas palavras de Magalhães Junior (1956), o príncipe de Joinville leva Francisca do severo e pobre palácio de São Cristóvão para o deslumbramento da pomposa Corte francesa, na qual se sentia desamparada, sem ambiente e esperançosa em encontrar uma amiga com quem pudesse exprimir-se em sua própria língua natal. "Príncipes, nobres, políticos, militares, e, sobretudo, princesas e damas, olhariam com algum desdém e superioridade a créole 3 que entrava com direitos de hierarquia e privilégios de precedência nos paços do rei de França". (PINHO, 1959, p. 194).

É nesse momento que a princesa Francisca encontrou na jovem viscondessa de Barral, sua patrícia e amiga, a confidente que precisava. Por isso, obteve de seu sogro que

\footnotetext{
1 Trecho de missiva minutada pelo Imperador para Paulo Barbosa, mordomo da Casa Imperial, sobre a contratação da preceptora governante para as princesas. Arquivo Paulo Barbosa - APB. Tomb. 2865/97. Museu Imperial//bram/MinC.

2 A condessa tinha um irmão, fruto de um romance do visconde com Françoise Elisabeth Dermé. Alexandre Sebastião Borges de Barros foi recomendado pelo pai ao seu amigo marquês de Marialva, responsabilizando-se, através de seu procurador, pelas despesas decorrentes com a educação do menino. Mais tarde, ele recebeu a herança que lhe era devida (FRANCISCO, 2017).

${ }^{3} \mathrm{Em}$ português, crioulo.
} 
a nomeasse sua Dama de Honor, com direito a talher na mesa do rei, além de carruagem da Casa Real. (MAGALHÃES JUNIOR, 1956).

Poucos anos depois, em 1847, a situação política na França tornava-se, mais uma vez, tumultuada, avizinhando-se os perigos que assombravam a nobreza, conhecedora da capacidade revolucionária do povo francês. Possivelmente, conscientes dos riscos que corriam, Luiza e o marido decidem retornar ao Brasil para uma temporada no engenho ${ }^{4}$. No ano seguinte, confirmando os prognósticos que já davam indícios anteriormente, estoura a Revolução de 1848 na França, o rei Luiz Filipe é destronado e a família Orléans refugia-se no Castelo de Claremont, no sul da Inglaterra, com o consentimento da rainha Victória. (MARIZ, 2016).

Longe da Europa inquieta, no Brasil, a família Barral fixava-se e acostumava-se na Bahia, quando em 1854, um acontecimento já não mais esperado ${ }^{5}$, ocorre na vida da viscondessa: nasce seu único filho, Dominique de Barral. Enquanto a viscondessa e sua família dedicam-se ao engenho, ao nascimento e aos cuidados com o filho, na Corte do Rio de Janeiro, a década de 1850 também começava e avançava com profundas mudanças.

Com a morte de Pedro Afonso6, herdeiro do Trono, o clima era de luto e de preocupação pelo futuro do Império brasileiro. Por sua vez, o destino de Isabel, filha mais velha do Imperador, tomava novos rumos. Aos quatro anos de idade, na falta de herdeiros do sexo masculino, ela é, então, reconhecida como sucessora de D. Pedro II no governo da nação, em uma cerimônia no Paço do Senado, no dia 10 de agosto de 1850 . Ao se tornarem, efetivamente, presuntivas herdeiras, Isabel e Leopoldina (na falta da primeira), também passam a ter novos significados para o Brasil, para a monarquia e, consequentemente, para o pai.

O Imperador manifesta-se que não obstante o "golpe recebido" era preciso empreender todos os esforços para a educação de suas duas filhas, a fim de que pudessem um dia "fazer a felicidade do país que as viu nascer". (AGUIAR, 2015, p. 56). De acordo com Aguiar (2015), o Imperador tinha consciência de que a condição ocupada por Isabel como herdeira da coroa demandava uma educação à altura do cargo que ocuparia. Para a autora, "a ela não seriam suficientes os ensinamentos das 'primeiras letras' e das 'prendas domésticas', como estabelecia a Constituição e permitiam os pais das meninas que estudavam no século XIX". (AGUIAR, 2015, p. 56).

Ainda assim, as preocupações de D. Pedro II indicam que a formação de "senhoras" teria prioridade sobre a de estrategistas políticas, em um país com severas estruturas patriarcais, como mostra seu registro, procurando estipular como deveria ser a formação de Isabel e Leopoldina,

\footnotetext{
${ }^{4}$ Em 1847, partia da França uma missão diplomática à China, a bordo da Bayonnaise, com escala na Bahia. Luiza e seu marido obtiveram licença para viajarem na embarcação de guerra e a viagem durou 74 dias (FRANCISCO, 2017).

5 A viscondessa já tinha 38 anos e escreve em carta a Paulo Barbosa: "Deus depois de me pôr velha quis dar-me uma grande consolação mandando-me do Céu um anjinho por filho". Carta datada de 26 de março de 1856. APB - Tomb.: 2861/97. Museu Imperial/lbram/MinC.

6 Sobre o assunto, consultar Aguiar (2015, p. 48-52).
} 
o caráter de qualquer das princesas deve ser formado tal qual convém a Senhoras que poderão ter que dirigir o governo constitucional d'um Império como o do Brasil. A instrução não deve diferir da que se dá aos homens, combinada com a do outro sexo; mas de modo que não sofra a primeira. ${ }^{78}$

Embora os primeiros escritos do Imperador já evidenciem seu posicionamento sobre a complexa tarefa que envolvia transformar uma filha mulher em suposta soberana do Trono brasileiro, é presumível que ele imaginasse as resistências e as expectativas, por vezes, funestas, que iria enfrentar, constatando a necessidade de alguém que se encarregasse de supervisionar, desde logo, a educação das princesas. Busca, então, inicialmente, indicações da madrasta, Amelia de Leuchtenberg ${ }^{9}$, que tendo convivido em diversas Cortes europeias e provido de uma excelente educação sua própria filha, poderia auxiliar no assunto, encontrando uma preceptora à altura da função.

Repousam nas pastas do Arquivo da Casa Imperial do Brasil (POB), no Museu Imperial em Petrópolis, duas páginas de rascunho de uma missiva de resposta, de $\mathrm{D}$. Pedro II para sua madrasta, Amelia de Leuchtenberg, não datada, mas, possivelmente, escrita em 14 de novembro de 1853, na qual o Imperador demonstra que já possuía detalhadas informações acerca do perfil da preceptora "ideal" para dirigir a educação de suas filhas. Contudo, não deixa de envaidecer a madrasta, fazendo-lhe o elogioso convite e afirmando que ela seria a pessoa mais indicada, assim como ele próprio, para ensinar as filhas, enobrecendo a tarefa que, na verdade, deveria ser exercida por alguém bem menos nobre que a "ex" Imperatriz, uma vez que teria que trabalhar, efetivamente, nessa função, como servidora da Casa Imperial, e precisava possuir habilidades, notadamente, mais delimitadas do que a simples condição de nascimento. Possivelmente, a Imperatriz jamais cogitou dela mesma se encarregar da educação das princesas, ciosa que era da sua condição de "Majestade Imperial" (TORRES, 1947), corroborando que as missivas do século XIX não podem ser lidas de forma literal, mas observando-se os códigos de etiqueta e civilidade que, naquele período, regiam a escrita epistolar, especialmente, entre membros da nobreza. (CUNHA, 2002).

\begin{abstract}
Muito Ihe agradeço a sua ultima carta, e n'ela vejo mais uma prova da amizade, que sempre procurará merecer quem tanto a respeita. Sempre julguei que seria tarefa difićlima encontrar uma senhora digna de dirigir a educação de minhas filhas, e por isso foi a minha primeira ideia rogar-lhe que d'ela se encarregasse. Mas ainda não me convenci da inutilidade de semelhante medida, atendendo à que as senhoras dos seus respectivos quartos ainda que muito cuidadosas (honra lhes seja feita) não possuem o grau d'educação que, mesmo na sociedade ordinária, se requer. O meu desejo seria tomar sobre mim este encargo, mas bem pode prever minha mãe que o tempo que me resta das minhas obrigações não m'o permitiria e além d'isso não sou dos mais habilitados para lidar com senhoras, principalmente com as d'esta casa que afora as ocasiões de serviço vivem na mais completa ociosidade. Eis a pura verdade, diga-me se não tenho razão de desejar ter junto as minhas filhas uma senhora de quem possa confiar também pelo lado da sua inteligência e polidez; portanto ainda insisto no meu segundo pedido e além das condições que naturalmente Ih'o ocorrerão animar-me-ia a lembrar-lhe as seguintes - alemã, católica romana e religiosa, viúva, sem filhos menores, maior de quarenta anos, sem pretensão, nem direito a esses de qualidade nenhuma sem interesses na Europa sabendo bem as línguas mais usadas, também entendendo o português ou que
\end{abstract}

${ }^{7}$ A ortografia das cartas e documentos citados foi atualizada para o português moderno.

${ }^{8}$ Atribuições da Aia, 1857. POB, Maço 29, doc. 1038. Museu Imperial/lbram/MinC - grifo nosso.

${ }_{9}$ Aguiar conta que mesmo distante dos enteados, Amelia de Leuchtenberg se fazia "presente" através das epístolas trocadas (AGUIAR, 2015, p. 61). 
venha depois de saber alguma coisa d'ele, para não estar sem ocupação quando aqui chegar; tendo gênio dócil maneiras delicadas e conhecendo perfeitamente os diversos misteres em que as senhoras passão as suas horas vagas. Quanto à instrução não exijo muito porque as minhas filhas hão de ter os mestres. Espero que minha [...] atenderá às minhas constantes rogativas, vindo a sua escolha dar prestígio a quem necessariamente há de ser por algum tempo alvo das censuras. ${ }^{10}$

Observa-se na carta detalhada, a preocupação do Imperador com a ociosidade e com as "horas vagas" femininas, aspectos que deviam ser bastante comuns nas senhoras que trabalhavam "nos quartos", as quais o monarca se refere, entre elas, as damas das princesas que deveriam ter como única atividade acompanharem-nas de dia até a noite, o que, provavelmente, deixava muitas horas vagas se tratando de apenas duas crianças e um séquito de "senhoras". Além disso, as mesmas não eram encarregadas da educação, mas somente do "serviço" que, nas palavras do próprio Imperador, só ocorria em determinadas "ocasiões".

Em que pesem as recomendações enviadas à Imperatriz Amelia e, talvez, a outros correspondentes na Europa sobre as características da preceptora pretendida, demonstrando a disposição de D. Pedro II para encontrar uma aia à "altura" da educação de suas filhas, é a irmã Francisca, princesa de Joinville, que dá ao irmão a resposta que ele tanto buscava. Em 07 de janeiro de 1856, de Richmond, na Inglaterra, ela escreve ao Imperador recomendando sua ex-dama de companhia. Segundo ela, nenhuma outra aia poderia ser melhor do que a "Barral". Contudo, temia que o marido e o filho pequeno da viscondessa fossem empecilhos para Luiza aceitar o convite, e, portanto, conhecedora da personalidade da viscondessa, bem como de seus anseios e aspirações, advertia que the fosse oferecida uma "posição mui boa", com casa ao "pé do Paço", para que ela pudesse ter interesse em assumir a função e, também, porque as benesses e deferências a ela concedidas iriam produzir autoridade sobre as outras damas. Em uma carta de quatro páginas, a princesa enaltece as qualidades de Luiza, buscando justificar sua veemente indicação.

\begin{abstract}
Meu querido Mano Pedro
Vou começar esta carta falando-te logo do que nos interessa tanto da escolha da Aia. Creio que não podias escolher melhor do que a Barral a qual não é só mui bem educada como maneiras e princípios sólidos em tudo. Mas também sabe bastante. Ela fala perfeitamente bem o francês, inglês e a sua língua. O piano também é muito forte. Toca perfeitamente bem. E creio que com mestres debaixo da sua vista e direção tudo poderá ir como o desejas e teres para suas filhas uma educação excelente. Creio que a Barral não há de poder seguir a educação a todos os instantes como faria uma institutrice que não tivesse interior, de maneira que creio que é indispensável de teres uma pessoa nessa posição e inteiramente debaixo das suas ordens. Duvido que aches alguém no Rio capaz disso e submetendo-se a ficar inteiramente debaixo das suas ordens, pudesse na Europa, mas isto ainda há de ser difícil. O que eu acho indispensável é de mudar inteiramente com a vinda da Barral o pessoal que está ao pé das tuas filhas. O que eu temo é que a Barral não aceite o posto tendo o seu marido e, sobretudo, o seu filhinho que ela mesma nunca deixa sozinho. Creio que lhe deves fazer o sacrifício de teres ao pé do paço o seu ménage do qual creio que ela nunca há de se separar sendo muito unido como ele é. É absolutamente necessário que ela tenha alguém em que se possa fiar inteiramente para ter horas no dia, ou puder ter a tarde e a noite para passar no seu ménage. Vejo que não pensas na fortuna que eles administrarão eles mesmos [...] de maneira que isto pode ainda ser um motivo para que lhes seja mais difícil aceitar
\end{abstract}

${ }^{10}$ Carta de D. Pedro II para sua madrasta, Amelia de Leuchtenberg. POB Cat. B, maço 29. Doc. 1046. Museu Imperial/lbram/MinC. 
o lugar. Para concluir o que eu penso, creio que deve lhes propor uma posição mui boa para que ela possa em tudo ficar o que ela deve ser ao pé das tuas filhas, senão tenho muito medo que as outras não se ponham todas a querer subir por cima dela e então fazer-lhe intrigas de todas as maneiras que ela seja obrigada a deixar o lugar e isto é sempre bem mas as mudanças continuas na regra da educação. Eu espero que a Barral aceite. Tanto que outra vez se quiseres que trate negócios para $\mathrm{ti}$, desejo que me fales com mais detalhes e que possa saber quais são as proposições que fazes a pessoa, pois com isso poderia arranjar os negócios melhor sabendo o que posso dizer e do que vou tratar [...]. Adeus meu caro Pedro. Aceite um abraço bem do coração. Desta tua bem afetuosa Mana Francisca. ${ }^{11}$

Luiza Margarida Portugal de Barros é considerada pela princesa de Joinville como, possivelmente, a única mulher no Brasil, e até na Europa, capaz de atender às expectativas para ser a preceptora de Isabel e Leopoldina, diante da pretensão de uma "educação excelente" que tal função implicava. Ao traçar um paralelo das missivas trocadas entre o Imperador com sua madrasta Amelia de Leuchtenberg e com sua irmã, princesa de Joinville, verifica-se que algumas das características almejadas por ele para a aia de suas filhas, podiam ser atendidas por Luiza: falava fluentemente o inglês, o francês e a sua língua natal; atendia a idade estipulada; lia e escrevia corretamente e com desenvoltura; e, ainda, tocava piano muito bem. Além disso, contava, com a importante aprovação do mordomo da Casa Imperial ${ }^{12}$ :

As recomendações de $\mathrm{D}$. Francisca foram reforçadas pelo testemunho do mordomo da Casa Imperial, Paulo Barbosa, que, na Europa, quando no exercício de suas funções diplomáticas, tivera oportunidade de privar com a Barral, de apreciar-Ihe as boas maneiras, a finura da inteligência e o encanto pessoal. (MAGALHÃES JUNIOR, 1956, p. 7).

Em que pese o cumprimento de parte das condições esperadas, a viscondessa não atendia às exigências quanto a "ser viúva", "sem filhos" e ser "alemã". Ou seja, não era apenas uma preceptora com boas referências a ser contratada na Europa, mas se tratava de uma mulher nobre, cujo estilo de vida era bastante mais complexo que o desejado. Todavia, convencido pela irmã, D. Pedro II incumbiu a Paulo Barbosa que entrasse em contato com Luiza e formalizasse o convite, para que, como aia principal, ela viesse supervisionar a educação de Isabel e Leopoldina, não só ensinando, mas também coordenando os demais mestres e reportando-se, apenas a ele, o Imperador, a fim de valorizar ainda mais a função.

A troca de correspondência entre o primeiro convite oficial do mordomo do Paço, Paulo Barbosa, em nome do Imperador, à viscondessa, iniciou por volta de março de 1856, mas somente foi concluída em junho desse mesmo ano, mediante 0 aceite das diversas condições impostas pela futura aia, que envolviam desde salário, tratamento, casa e sege próprias no Rio de Janeiro, até o custeio para o deslocamento da família da Bahia.

O Imperador cedeu a todas as "exigências" da viscondessa, até mesmo interferindo no processo de contratação, ao ver que ele não avançava na velocidade que esperava. Em carta minutada ao mordomo do Paço, D. Pedro II escreve:

\footnotetext{
${ }^{11}$ Carta da princesa de Joinville a D. Pedro II. Arquivo Grão-Pará, Museu Imperial. AGP - XXVIII-1.

12 Paulo Barbosa da Silva era o mordomo interino da Casa Imperial, encarregado dos assuntos de cerimonial e etiqueta e supervisionava os funcionários (criados particulares e empregados honoríficos): damas, veadores, guarda-joias, aios, camaristas, etc. (FRANCISCO, 2017).
} 
A aia para as Princesas é cada vez mais precisa, para a conveniente educação. 'A Viscondessa de Barral é quem reúne a maior parte das condições desejadas para semelhante cargo, e, portanto, estou pelas condições propostas, ficando bem claro que ela há de morar nos lugares determinados pelo papel que the mandei de Petrópolis'. (MONTEIRO, 1962, p. 32, grifo nosso).

Após muitas indagações sobre o lugar que teria na Corte carioca, a carta que respondia aos questionamentos da viscondessa, informava que ela seria feita "Dama" da Imperatriz, ocupando assim, uma categoria superior a quase todos os servidores da Casa Imperial. (VASCONCELOS; FRANCISCO, 2014). Salientava, ainda, que todas as questões relativas à educação das princesas estariam sob a sua vigilância. Quanto à moradia, poderia ter lugar no Paço de São Cristóvão, ou da cidade, ocupando os aposentos que tinham pertencido à condessa de Belmonte ${ }^{13}$, com entrada separada. Caso houvesse necessidade de uma Institutrice, seria escolhida a partir da indicação da viscondessa a quem ficaria subordinada "em tudo e por tudo". Comeria à custa do Imperador e no seu aposento. Receberia doze mil francos por ano e uma pensão vitalícia de metade desse valor, depois de finda a educação das princesas ${ }^{14}$. Também a cargo do Imperador ficaria a educação de Dominique, seu filho, até que tivesse uma carreira. Teria carro para andar. Ou seja, todas as reivindicações eram atendidas, além de serem suplementadas com oferecimento de um alto salário e uma pensão vitalícia. Magalhães Junior (1956, p. 13), ao analisar essas cláusulas estabelecidas, explica que a remuneração recebida pela viscondessa de Barral como preceptora das princesas "não era menor" do que as de um ministro de estado com assento no Senado ou na Câmara.

Com as condições de trabalho acordadas, ciente de suas prerrogativas, da posição que ocuparia na Corte e dos benefícios que lhe seriam outorgados, a viscondessa ainda faz registrar os gastos e dispêndios que teria com a sua mudança, que envolvia ela, a família e, pelos termos da carta escrita por ela ${ }^{15}$, "todos" os seus parentes, além dos criados e escravos. Também, queixa-se de ter que abandonar suas propriedades, o que causaria muitos prejuízos, que só poderiam ser compensados com uma casa mobiliada, uma sege "decente", os doze mil francos oferecidos e a pensão vitalícia de seis mil francos anuais. Enfim, aceitos os termos do acordo, ela estava pronta para partir para o Rio de Janeiro, quando o Imperador julgasse conveniente.

Perante a anuência das partes sobre os termos estabelecidos, Paulo Barbosa trata de responder rapidamente à viscondessa, dando por encerradas as negociações e tentando obter de Luiza, uma data para sua chegada à Corte. Em missiva escrita no dia 22 de junho de $1856^{16}$, novamente em papel timbrado de negro em sinal de luto, Luiza prontifica-se a embarcar no último dia de julho, solicitando que um vapor venha buscá-la. Todavia, já era condessa de Barral, tendo em vista a morte do sogro, ocorrida recentemente. $\mathrm{O}$ título de conde do sogro foi herdado pelo marido e, por conseguinte, ela passou de viscondessa à

\footnotetext{
${ }^{13}$ Mariana Carlota de Verna Magalhães Coutinho, primeira e única condessa de Belmonte, foi camareira-mor na época do Primeiro Império e a responsável pelos estudos iniciais de D. Pedro II, desenvolvendo a função de aia do Imperador, quando ainda menino (MARIZ, 2016).

14 Carta enviada por Paulo Barbosa à viscondessa de Barral. APB - Tomb.: 2862/97. Museu Imperial//lbram/MinC.

${ }^{15}$ Carta enviada pela viscondessa de Barral a Paulo Barbosa, em 25 de maio de 1856. APB - Tomb.: 2863/97. Museu Imperial//bram/MinC.

${ }^{16}$ Carta enviada pela condessa de Barral a Paulo Barbosa, em 22 de junho de 1856. APB - Tomb.: 2869/97. Museu Imperial//bram/MinC.
} 
condessa de Barral e marquesa de Monferrat. Assim, quando Luiza chegou ao Rio de Janeiro e iniciou o trabalho de aia das princesas já possuía o título de condessa.

No dia 28 de julho, uma corveta de guerra ${ }^{17}$ parte para buscar na Bahia a preceptora das princesas brasileiras, nomeada "Dama de Palácio" 18 , por Decreto de 31 de agosto de 1856, levando-a, com grandes honras, para o Rio de Janeiro. Em menos de um mês, "no dia 25 de setembro", outro Decreto, "n 417", era expedido, referendado por Paulo Barbosa, concedendo à aia das princesas a quantia de "um conto de réis por mês" e mais "dois contos anuais" para moradia. Constava ainda do mesmo Decreto a autorização para que o mordomo da Casa Imperial mobiliasse a residência em que Luiza iria residir. (LACOMBE, 1944, p. 24; LYRA, 1977, p. 315).

O folhetim A Semana do Jornal do Commercio, datado de 27 de julho 1856, ao informar sobre a escolha e vinda de Luiza para cuidar da educação das princesas, destacava que ela reunia "todos" os requisitos necessários bem como os títulos desejáveis para que desempenhasse a missão que lhe havia sido confiada, enaltecendo seu parentesco: "A condessa escolhida para governante ou aia das princesas brasileiras é filha do nosso falecido visconde da Pedra Branca e esposa do conde de Barral, filho do conde do mesmo título, que ainda este ano sentava-se no senado de França".

Assim, se iniciou uma relação de trabalho, que por todas as suas características, além da condição social dos envolvidos, acabou se tornando uma longeva amizade, perdurando para além do casamento das princesas e que, de alguma forma, certamente, interferiu no desfecho do destino das três mulheres.

\section{A condessa e as princesas: estratégias de educação para uma formação singular}

Em seu diário, a princesa Isabel registra em 09 de setembro de 1856, o primeiro dia com sua preceptora: "Veio hoje, pela primeira vez, minha aia a Condessa de Barral, e dei com ela princípio ao estudo da língua francesa, dei lição de piano". ${ }^{19}$ Começava neste dia um processo de educação que, embora não fosse o mais adequado para um príncipe que iria ascender à linha sucessória e governar um país com problemas que iam da demarcação de fronteiras à pressão inglesa contra o tráfico de escravos, era aquele que a condessa de Barral entendia como o mais apropriado, reunindo a "boa educação" feminina, com disciplinas consideradas imprescindíveis à formação de um futuro soberano. Argon (2009, p. 102) pontua que "por determinação de D. Pedro II", a educação da princesa Isabel, "deveria ser a mesma dispensada aos homens daquela época, mas aliada à das mulheres, que visava ao desempenho das atividades domésticas e ao bom comportamento nos salões". À Leopoldina foi dispensada a mesma atenção, inclusive curricular, tendo em vista

\footnotetext{
17 Tratava-se da corveta Recife, "comandada pelo $1^{\circ}$ tenente Delfim Carlos de Carvalho, futuro barão da Passagem". A corveta, ao chegar à Bahia, ficou ancorada alguns dias para receber os preparativos da mudança (MAGALHÃES JÚNIOR, 1956, p. 12). "Após levantar âncora, com quatro dias de viagem desde a Bahia, chegou ao Rio de Janeiro em 31 de agosto de 1856, data do Decreto de Nomeação da Condessa de Barral, com quem vinham seu marido, seu filho, três criados e quatorze escravos". (JORNAL DO COMMERCIO, Rio de Janeiro, $1^{\circ}$ de setembro de 1856).

18 "Dama de Palácio" é a expressão que consta no Decreto de 1856, que nomeia a condessa como preceptora das princesas imperiais brasileiras. (LACOMBE, 1944, p. 24).

19 Anotação no diário da princesa Isabel, então com 10 anos de idade. 09 de setembro de 1856. Museu Imperial/lbram/MinC.
} 
que, na falta da irmã mais velha, a filha caçula passaria a ser a herdeira do trono. (AGUIAR, 2015).

Todavia, com aquiescência do Imperador, ou não, os temas tratados nas cartas, tanto da condessa como das princesas, evidenciam que o "desempenho das atividades domésticas" e "o bom comportamento nos salões" era bem mais apreciado pelas alunas do que o leque de disciplinas estudadas que, talvez, até por sua dosagem exagerada ${ }^{20}$, acabou por não passar de conteúdos memorizados, alijando, especialmente Isabel, de tomar parte nos acontecimentos políticos da nação, acompanhar o pai nas decisões de gabinete, ou experimentar a resolução de questões postas cotidianamente a um governante, considerando que a condessa, desde o início, impôs rígidas normas, pelas quais se depreende que as princesas eram vigiadas, dia e noite, em suas atividades, incluindo-se tudo que era conversado, lido e escrito por elas. (FRANCISCO, 2017).

Já imbuída de plenos poderes em sua função, a condessa passou a escolher os mestres para conduzirem as disciplinas que seriam ensinadas e a cuidar também do comportamento pessoal das meninas, incluindo os hábitos da toalete. Em missiva datada de 06 de novembro de 1859, em papel timbrado com a coroa de conde em carimbo seco, e cinco páginas de texto, Luiza descreve para a Imperatriz o cotidiano das meninas. Conta da valentia de Leopoldina ao arrancar um dente e dos onze banhos frios que Isabel tomara. Justificou que Leopoldina tomara apenas nove pela perda do dente, pois a cissura precisava cicatrizar. Conta que a menina estava mais gordinha, com "linda cor", e que estava "ficando bonitinha". Quanto à Isabel, com quem a condessa era bastante rigorosa com o comportamento e a aparência, segundo ela "estava muito gorda". No entanto, a preceptora dissipa a queixa com a afirmação de que sua "bondade" e "candura", cada vez mais, conquistavam seu coração. ${ }^{21} \mathrm{~A}$ condessa tinha uma maneira peculiar de fazer suas observações aos Imperadores, amenizando o que havia afirmado, após a reclamação.

Outra passagem da mesma carta informa que "a semana do Dr. Freire 22 foi aproveitada para a botânica, e se as palestras não foram tão alegres como na Semana do Persiani, não deixaram de ser interessantes", de onde se infere que a ludicidade esperada pela condessa era muito mais afeita à formação de uma princesa como a de Joinville, cujo papel dificilmente seria maior do que a boa apresentação nos salões da Corte, como consorte do seu príncipe, do que a imensa responsabilidade que se esperava do próximo soberano, de um país diante de inúmeras tensões e conflitos.

Na semana seguinte, no dia 11 de novembro de 1859, escrita em quatro páginas, com papel timbrado com coroa de conde em carimbo seco, Luiza escreve à Imperatriz, dando mais um exemplo de como estendia suas funções para muito além da supervisão educacional:

Rogo a V. Ma de instar com S. A. a Princesa D. Leopoldina para que se corrija do mau hábito que tem de estender o lábio inferior, de coçar a cabeça e o nariz, e de

20 Destinadas a governar homens, as jovens princesas foram instruídas como homens. Aprenderam Latim, Grego, Física, Química, Zoologia, Botânica, Filosofia, Álgebra e Trigonometria. Foram Bacharéis em Letras (sem o diploma) e doutoras em Direito, com complementação em direito civil, administrativo e constitucional. (SAINT-GEORGES, 1891, p. 415).

${ }_{21}$ Carta da condessa de Barral para a Imperatriz. 06 de novembro de 1859. CCCXXXVII - 7 - (1) - Arquivo Grão-Pará, Museu Imperial/ Ibram/MinC.

22 Francisco Freire era botânico e doutor em medicina pela Faculdade de Paris. Atuava, nessa época, como médico da Imperial Câmara. (FRANCISCO, 2017). 
vesgar os olhos quando escreve. Diga-lhe que espera achá-la sem esses cacoetes na Sua volta, para ver se Ela atende às minhas constantes advertências. - Não temos tido grandes tempestades de gênio ${ }^{23}$, apenas alguns aguaceiros que passam, coitada, sem rancor. ${ }^{24}$

O conteúdo dessas cartas é revelador de muitas leituras, mas, entre elas, do cotidiano das duas meninas, constantemente longe dos pais que, devido a sua posição, deixavam a educação de ambas, integralmente entregue à autoridade da preceptora. Soma-se a isso o fato de que a condessa tinha a expectativa, quando chegou ao Rio de Janeiro, de encontrar duas crianças já educadas de acordo com a sua condição de infantas e, no entanto, depara-se com um cenário no qual as princesas tinham como aias mulheres do povo ou antigas damas palacianas, pouco versadas nas artes da etiqueta $e$ comportamento esperados de príncipes herdeiros de um Império. A condessa, desde que constatou essas deficiências na educação das princesas, investiu em saná-las, priorizando hábitos, protocolos, lições morais ${ }^{25}$, agindo de forma enérgica, com a aquiescência do Imperador e da Imperatriz que, para compensar a suposta carência de uma educação adequada, deram à condessa plenos poderes de atuação, além de a mãe ter outras obrigações cerimoniais que a mantinham afastada, mesmo dentro do palácio.

Uma das primeiras atribuições acordadas por Luiza com Paulo Barbosa, havia sido sobre a escolha da institutrice. E foi exatamente por aí que ela começou seu projeto de formação das duas meninas. Vitorina Templier ou mademoiselle Templier, foi escolhida para ser ajudante encarregada da educação das princesas. Além dela, a condessa selecionou todos os outros mestres que atuaram na educação de Isabel e Leopoldina, como demonstram as cartas e documentos do período, muitas vezes, assistindo as suas lições. Alguns eram autores famosos, outros, músicos em ascensão, outro, pintor de destaque, cada qual colaborando na estratégia pedagógica planejada pela condessa, para que as futuras herdeiras do trono tivessem aquilo que ela entendia como sendo uma formação sólida e culturalmente prestigiada. Além dos mestres, a condessa aproveitava toda a ocasião em que a Família Imperial fosse visitada por celebridades da época, para que as mesmas dessem "lições" às princesas. Um exemplo disso é a carta de 18 de dezembro de 1859, da condessa para a Imperatriz, na qual é relatada a visita do padre Neville que, demorando-se três dias em Petrópolis, "deu ótimas lições de inglês"26. E ainda na mesma epístola: "Quando o Bevilacqua vem, para aproveitar seu tempo mando Suas Altezas tocarem a 4 mãos de noite as peças que sabem e isso serve de lição e vai desembaraçando-as alguma coisa". Ao finalizar essa missiva, a condessa, de forma dissimulada, demonstra que tinha consciência do papel que exercia e da aprovação dos Imperadores, quando, afirma: "Faço meu possível para desempenhar bem a minha missão, mas nunca tanto quanto eu quisera".

Foram muitos os mestres famosos e anônimos que participaram do projeto educacional da condessa para as princesas. Jules Toussaint, como professor de dança;

${ }^{23}$ Ao que parece, Leopoldina era mais arredia do que Isabel em atender as advertências da condessa. (FRANCISCO, 2017).

${ }^{24}$ Carta da condessa de Barral para a Imperatriz. 11 de novembro de 1859. 06 de novembro de 1859. CCCXXXVII - 7 - (1) - Arquivo Grão-Pará, Museu Imperial//bram/MinC.

25 Sobre o assunto, consultar Aguiar (2015).

${ }^{26}$ Carta da condessa para a Imperatriz, em 18 de dezembro de 1859. 4 páginas de texto. CCCXXXVII - 7 (1) - Arquivo Grão-Pará, Museu Imperial//bram/MinC. 
Joaquim Manuel de Macedo, autor de A Moreninha e O moço Loiro, como professor de História; Victor Meirelles como professor de desenho, entre outros tantos nomes que podemos encontrar facilmente na história do século XIX. À condessa, por sua vez, "segundo um escritor da época, monsenhor Joaquim Pinto de Campos, várias vezes deputado por Pernambuco e autor da primeira biografia de Pedro II, à 'respeitável Sra. Condessa de Barral cabia ensinar pedagogia'"27. (MAGALHÃES JUNIOR, 1956, p. 15).

A condessa também dava lições às princesas, mas sua principal função era a elaboração dos planos de estudo ou de aulas, que eram preparados semanalmente, para atividades de segunda a sábado. No arquivo Grão-Pará, sob a guarda do Museu Imperial, constam vários registros dos seus planejamentos semanais. Os do ano de 1858 são feitos em um caderno simples, de tamanho pequeno $(21,3 \times 3,7 \mathrm{~cm})$ pautado, que, atualmente, não apresenta capa. Nos planos de estudos traçados percebe-se que a condessa fazia, na verdade, "indicações das lições", o que sugere a possibilidade de não ser um planejamento inflexível, ou seja, não obstante a sua indicação do que deveria ser estudado naquele dia, seria admissível haver uma troca de tema ou, até mesmo, de disciplina.

Contudo, para o dia de atividades, a condessa estabelecia um rígido cronograma, cujos horários começavam as 6 e meia da manhã e iam até a noite, com pausas apenas para receber as visitas agendadas e aprovadas pela preceptora e pelos Imperadores, além do banho, das refeições e dos recreios. Na Figura 1, a seguir, observa-se um cronograma da princesa Isabel. A princesa, antes do banho, iniciava seu dia com meia hora de estudo.

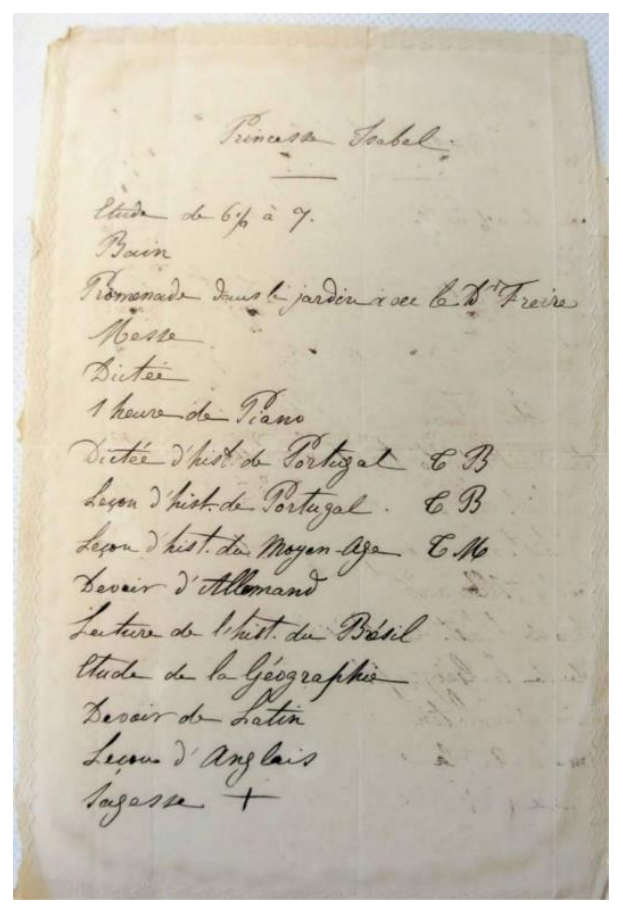

Figura 1 - Cronograma de estudo da Princesa Isabel. S/d.

Fonte: Arquivo Grão-Pará. Museu Imperial/lbram/MinC.

Verifica-se nesse exemplo de plano de estudos, que as lições tinham um cunho,

27 "Um apontamento de um professor dos príncipes define a educação da época: 'Pedagogia é a arte de educar as crianças, abrange a educação destas física, intelectual e moralmente. Data desde os tempos mais antigos e tem sido muito aperfeiçoada nos tempos modernos"'. (GUEDES, 2004, p. 98). 
sobretudo, histórico, sucedendo-se uma atrás da outra, em francês, o que dá uma ideia do quão maçante deveria ser colocá-lo em prática, assim como havia uma sucessão de professores, cada um buscando fazer do seu conteúdo algo relevante para a formação das princesas. Além disso, a cada lição, como demonstra a Figura 1, era atribuído um conceito também em francês, classificados em regular $(\mathrm{M}=$ moyen), bem regular ( $\mathrm{TM}=$ trés moyen), suficientemente bom ( $\mathrm{AB}=$ assez bien), bom ( $\mathrm{B}=$ bien), bastante bom ( $\mathrm{BB}=$ beaucoup bien), muito bom (TB = trés bien) e, como nota máxima, o perfeito (parfait). Essas notas, conforme observam Argon (2009) e Aguiar (2015), eram aplicadas aos vários tipos de exercícios: leitura, ortografia, ditado, gramática, análise, composição, tradução. Imperador recebia, semanalmente, um mapa com as notas das filhas. Por diversas vezes, o conceito de Leitura em Francês, na avaliação da condessa, que havia sido educada na França, tinha como rendimento final apenas B (bom).

Outro ponto interessante sobre a atuação pedagógica da condessa, é que pelos registros de Saint-Georges (1891), faltavam, à época, bons livros de História escritos em português. Como a condessa julgava inapropriados os manuais dos quais dispunha para o ensino da história de Portugal e do Brasil, resolveu ela mesma redigir um manuscrito para ministrar seu curso às princesas ${ }^{28}$. Para sua surpresa, já no primeiro dia em que começou a ministrar as aulas, deparou-se com o Imperador que chegava para assistir às lições. Conforme o relato de Saint-Georges (1891), na ocasião, a condessa teria dito que aquela havia sido uma das maiores emoções da sua vida. Todavia, não demorou a se recompor e acrescentar: "É bem verdade que no dia seguinte quando foi a vez do Imperador de dar a lição, ele estava mais emocionado e intimidado do que eu mesma tinha estado. Isto me deu, para o futuro, maior segurança". (SAINT-GEORGES, 1891, p. 415).

A condessa preocupava-se minuciosamente com as pessoas que se aproximavam das princesas e com as quais elas mantinham qualquer tipo de contato. Desse rol não estavam excluídos os professores, damas, amigas e auxiliares dos serviços nos Paços. Para tanto, usava de seus vastos conhecimentos sobre a aristocracia brasileira, as origens de cada família e sua importância política. Pouco a pouco, estendia essas informações ao Imperador, trocando com ele impressões sobre personalidades, lugares, instituições etc. Essa prática usada, inicialmente, para o controle em torno das princesas, acabou por também ampliar a influência da Barral sob D. Pedro II, para muito além da simples escolha de mestres.

Luiza tinha um temperamento forte, mas era capaz de dissimular atitudes que a desagradavam, especialmente nas princesas, observando o momento exato para corrigilas, por vezes, utilizando a interferência dos pais. Esse traço de sua personalidade pode ser verificado em grande parte de seus escritos que contém aspectos autobiográficos, nos quais ela demonstra profunda capacidade de disfarçar suas emoções, utilizando sempre um tom cortês e altivo.

Para as princesas era a "Condessinha", amável, que se dedicava e tinha como fim último que elas tivessem uma boa educação, adequada ao lugar para o qual estavam destinadas. Ambas as princesas registram em seus diários que ela lhes despertava um amor filial. Provavelmente, um dos aspectos que contribuiu para essa relação estrita, é que

28 Segundo informações colhidas nos textos pesquisados, esse manuscrito estaria sob a guarda da família. Ao que parece, Dominique o guardou por muitos anos a espera de uma futura impressão. (FRANCISCO, 2017). 
a condessa sabia delegar ao pai, o Imperador, a tarefa de chamar-Ihes atenção, ainda que ela tivesse o controle de tudo e fosse a principal informante do que se passava no cotidiano do palácio.

Um exemplo de que ela atribuía ao Imperador a tarefa de chamar a atenção das princesas, é um bilhete no qual Leopoldina pede ao pai um tempo extra para terminar um exercício de botânica que não havia concluído devido ao mau tempo ${ }^{29} \mathrm{e}$, ainda, por achar que Isabel teria tido mais tempo para se divertir. Este responde no mesmo papel que não concederia o que ela estava lhe pedindo porque, além da responsabilidade de aprender a lidar com o tempo, era preciso que ela respeitasse os professores. Fica clara a interferência da condessa que, notoriamente, só transferia ao Imperador esse tipo de decisão quando tencionava negá-la.

Outro aspecto que emerge na condução da educação das princesas pela condessa é o desvelo com o capricho, a limpeza e a organização, que pode ser notado na exigência de que os escritos não contivessem rasuras e borrões. Tal proibição requeria extremo cuidado ao lidar com a pena e o tinteiro, pois levar a tinta sem pingar até o papel era algo que a preceptora exigia, já que o uso do mata-borrão deixava marcas, as quais eram jocosamente censuradas por ela. A Figura 2, a seguir, mostra uma marca no papel que, possivelmente, foi causada pelo mata-borrão para retirar o excesso de tinta, e que deixou manchada a borda do papel. Quando isso ocorria, a condessa desenhava um rato aproveitando as manchas, para demonstrar que o descuido significava algo inapropriado. Assim, "De um borrão se faz um rato. É a moda da Condessa".

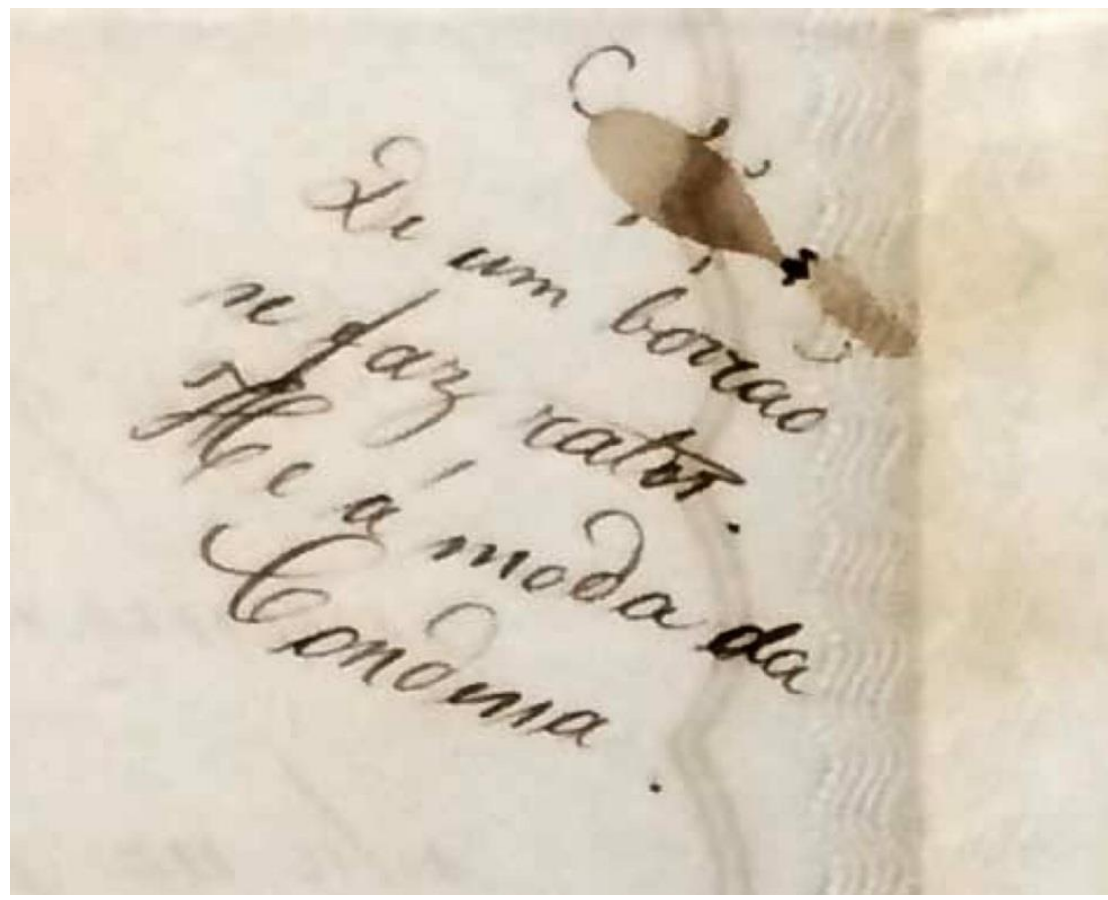

Figura 2 - Carta da princesa Isabel para o Imperador D. Pedro II, em 26 de março de 1861.

Fonte: Arquivo Grão-Pará. Museu Imperial//bram/MinC.

Três outros curiosos registros descansam, em pastas separadas, no mesmo

29 Sobre o assunto, consultar Argon (2006, p. 74-77). 
Arquivo Grão-Pará. Luiza, Isabel e Leopoldina narram o inóspito episódio. No Natal de 1859, os Imperadores estavam em viagem pelo norte do país. Na ausência dos pais, a condessa tratou de montar uma árvore de $\mathrm{Natal}^{30}$ na sala de jantar do Palácio em Petrópolis. Durante o mês, Isabel e Leopoldina haviam passado "maus bocados" com o cirurgião-dentista da Casa Imperial, Henrique Lemale. Isabel arrancou um dente mole, "chumbou" e "limou" outro; ao passo que Leopoldina "chumbou" um "queixal". A condessa, então, resolveu colocar embaixo da árvore quatro presentinhos de Natal, trazidos pelo "Noel" às crianças. Qual não foi a surpresa das princesas ao verificarem que os presentes eram palmatórias!

O relato surpreendente do ocorrido aos Imperadores, feito tanto por Luiza ${ }^{31}$, como por Isabel, mostra que a condessa não abria mão de nenhuma oportunidade para dar uma lição do que ela julgava como um aprendizado às princesas. É ela mesma quem descreve para a Imperatriz, como ocorreu a entrega dos presentes:

[...] mas Elas por sua bondade acolheram assim mesmo bem, as ridicularias que Ihes oferecemos, e riram muito das 4 palmatorinhas que o Bom homem Noël mandou A mais Teimosa, À mais preguiçosa, À que troca letras, À quem não sabe taboada. Dizendo logo cada uma Princesa que Ihe pertencia uma palmatorinha $[\ldots]^{32}$

Isabel também escreve para a mãe, contando sobre a noite de Natal e sobre os inusitados presentes, na carta-diário, iniciada no dia 23 de dezembro e escrita até o dia 26 de dezembro de 1859. No texto do dia 24, conta sobre as palmatórias com seus "destinatários" e não se contém em registrar: "Desejava bem que meus Caros Paes estivessem cá"33.

Utilizando uma de suas tantas estratégias psicológicas, nas quais procurava despertar remorso, vergonha, medo entre outros sentimentos nas pupilas, a condessa tinha como corrente "pedagógica" algo muito em voga, na época, para substituir os castigos físicos, que eram os castigos morais. Tais práticas, muito usadas pelas mestras que se diziam discípulas de Rousseau, consistiam em levar o aluno a arrepender-se de sua falta diante da constatação do mal que havia causado. Assim, procedia também a condessa, segura de que, para aquele tempo e contexto, essa era a melhor maneira de educar duas crianças nobres. (VASCONCELOS, 2005).

Além da constante presença física da condessa no dia-a-dia das princesas, desde que acordavam até a hora de deitarem, ela também enviava mensagens por cartas quando estava ausente. Essa onipresença e controle absoluto de tudo que se passava na vida das meninas, era uma rotina, mesmo quando se tratava apenas de um final de semana longe das princesas. Para tanto, não havia limites e a condessa era capaz de se transformar numa "fadazinha" que tudo via e tudo sabia:

\footnotetext{
${ }^{30}$ A nossa árvore de Natal foi muito bonita e me lembrou muito a que nós tínhamos, graças a nossa boa Condessinha [de Barral]. Carta de Leopoldina a Isabel. Viena, 03 de janeiro de 1867. XLVIII-2 (04). Arquivo Grão-Pará, Museu Imperial/lbram/MinC.

${ }^{31}$ Carta da condessa de Barral para a Imperatriz. Petrópolis, dezembro de 1859. A carta contém quatro páginas de texto escritas, em papel timbrado com a coroa de conde em carimbo seco. Arquivo Grão-Pará, Museu Imperial//bram/MinC.

32 Carta da condessa de Barral para a Imperatriz, em dezembro de 1859. Arquivo Grão-Pará, Museu Imperial/lbram/MinC.

${ }^{33}$ Carta da princesa Isabel para a Imperatriz. Petrópolis, 24 de dezembro de 1859. Arquivo Grão-Pará, Museu Imperial/lbram/MinC.
} 
Minhas queridas Princesas

Disse que não escreveria hoje, mas sinto tantas saudades a estas horas que sempre passo aos Sábados na companhia de Vossas Altezas, que não posso resistir ao desejo de conversar um bocadinho com as minhas queridas Princesas. - Não vão pensar que fiquei no Rio, estão muito enganadas, meu coração partiu com Vossas Altezas e por lá anda. Hoje devo a esse propósito, Ihes fazer uma grande confidência e vem a ser, que: eu sou um ente encantado que tem íntimas relações com uma fadazinha, essa minha amiga emprestou-me um anel que me torna invisível e é por isso que Vossas Altezas não me podem ver, e eu às vezes lhes adivinho os mais íntimos pensamentos - Ora hoje, por exemplo, eu tenho visto tudo quanto Vossas Altezas tem feito, e muito contente fiquei quando ao entrar do portão de Petrópolis Vossas Altezas olharam para minha casa e disseram uma para outra "Olha Mana, a casa da Condessa". Quando entraram no Palácio lá acharam o Andrade Pinto o Dr. o Gorducho etc etc e já o Sr Bogario Ihe tinha feito sua barreteada... É verdade ou mentira? Quando entraram $\mathrm{p}^{\mathrm{a}}$ nossa sala d'estudo ainda viram garatujas do Candido Baptista no tableau noir, subiram $p^{\underline{a}}$ o quarto (mas eu que mesmo disfarçada não sou indiscreta) fiquei cá embaixo, mas sempre ouvi algum barulho, e parece-me que ambas as Princesas exigiram imediatamente com mil cousas impossíveis, e que foram resmelengando $\mathrm{p}^{\mathrm{a}}$ a Casinha. - Nessa casinha lembraram-se outra vez da Condessinha e ela ficou tão contente! ! O Palácio está muito adiantado la grue trabalha com vigor, e o Jacob cuido muito nos jardins de S.S.A.A. não é assim?

A fadazinha acaba de me dizer, que as Princesas gostam de paté de Regnaud e dessas bolachinhas $p^{\underline{a}}$ roer amanhã no carro, vão pois bolachinhas e paté de Regnaud. Vossas Altezas não se esqueçam da promessa que me fizeram descrever o diário de sua viagem, não omitam nada, porque tudo me interessará vivamente. Eu também tenho meus projetos de patuscadas, e tudo contarei qdo voltarem. Queiram por mim beijar a mão de Papá e de Mamã e com afeto me recomendar a todas as minhas companheiras. Eu terei o cuidado de ir visitar a Snra. D. Ritta e tomara que ela queira vir passar um dia comigo. ${ }^{34}$

Anunciando uma presença invisível capaz de ler os mais íntimos pensamentos das duas meninas, a condessa impunha seus ensinamentos mesmo à distância, fazendo-as crer, ainda que envolta a fantasia das fadas, que nada era possível de ser escondido da preceptora. Dessa forma, ela mantinha as princesas submissas a suas determinações, embora estivesse distante.

Apesar da metáfora da amiga fadinha ser apenas uma forma de lembrar as princesas de suas tarefas rotineiras, ela revela uma infantilização e um tratamento peculiar entre a preceptora e suas pupilas que se estenderá por toda a vida, fazendo com que Isabel mesmo depois de casada dependesse dos conselhos da Barral para suas decisões. Tal fato é apontado pelo próprio conde d’Eu em carta que escreveu para sua avó, a rainha Maria Amélia:

Madame de Barral teria muito desejado nos acompanhar e ainda o quer, sobretudo, a fim de conduzir Isabel em vossa presença. Quanto ao meu consentimento pessoal nada a dizer, pois fiquei também encantado com ela, pois é uma pessoa muito inteligente, notavelmente serviçal e que tem dado ótimos conselhos. Mas ficou estabelecido que no dia do seu casamento Isabel se separaria das pessoas que a educaram, e eu não quero fazer uma exceção em favor de madame de Barral apesar da estima que tenho por ela. (SAXE-COBURGO E BRAGANÇA, 2012, p. 98).

O duque de Saxe, marido de Leopoldina, não coadunava totalmente com a opinião do conde d'Eu. Em carta endereçada à princesa Clementina, em 06 de outubro de 1864,

${ }^{34}$ Carta da condessa de Barral, para as princesas Isabel e Leopoldina. Rio de Janeiro, 22 de junho de 1861. Arquivo Grão-Pará, Museu Imperial//bram/MinC. 
ele escreve que "aqui é Madame de Barral que dirige tudo e assim o Imperador faz tudo aquilo que ela pede, o que a deixa envaidecida". (SAXE-COBURGO E BRAGANÇA, 2012, p. 98). Em 07 de novembro de 1868, a opinião do duque de Saxe sobre a condessa havia piorado e ele escreve à princesa Clementina, dizendo:

A senhora sabe que a Condessa de Barral é um pouco queimada conosco. Não saberia por quê. Ela queria retornar a sua antiga posição, tão poderosa, e como ela não conseguiu é furiosa contra todos nós. Nem nós podemos escapar. Ela não é amável como toda a nossa família; mas tanto pior, eu não me importo nada dessa velha governante. (SAXE-COBURBO; BRAGANÇA, 2012, p. 271).

Outro aspecto que sobrevém da análise do cotidiano das princesas sob a condução da condessa é o tratamento diferenciado dispensado a Isabel e Leopoldina. Depreende-se das fontes que Isabel era preferida e isso não se dava apenas por se tratar da herdeira, mas, também, porque ela possuía traços de personalidade mais dóceis e mais sensíveis às exigências da preceptora, ao passo que Leopoldina possuía um gênio mais difícil, e era propensa a cenas de mau humor e intolerância a determinadas ordens. Assim, as queixas mais constantes da condessa eram referentes à irmã caçula, para a qual se encontram os principais registros de cartas que continham admoestações.

No entanto, a carta transcrita a seguir, datada de 29 de junho de 1863, quando Barral adverte a própria Isabel que já tem quase 17 anos, demonstra que as correções e castigos imputados pela preceptora não ficaram restritos à infância, mas antecederam as vésperas do casamento.

\begin{abstract}
Minha querida Princesa,
Creia que sofri mto hoje mortificando-a tanto, mas talvez nunca the desse maior prova de amor. Triste prova de amor dirá V.A., e na verdade mto custa abdicar o papel de sua Camarada $p^{a} m$ ' enfronhar na severidade de sua governante, mas que remédio, se V.V.A.A. não se querem emendar de outro modo!... Lembre-se $\mathrm{m}^{\mathrm{a}}$ querida Princesa que V.A. vai breve ter 17 anos e que não deve mais perder um só dia $\mathrm{p}^{\mathrm{a}}$ corrigir o que por demasiado amor e indulgência temos todos mais ou menos tolerado até aqui! [...] Então Vossa Alteza me agradecerá as lágrimas que eu fiz correr hoje e que sem dúvida seu anjo da guarda aparou e levou a Deus! Aceite bons conselhos de todos, e fique certa, que qto mais dócil se mostrar, mais querida será de todos, e qto mais humilde mais abençoada será por Deus. Se não lhe desse um apertado abraço antes de me deitar, não descansaria tranquila, perdoai essa confiança a sua velha criada mto amte. e obrig. Ctesse de Barral Dia de São Pedro! $!^{35}$
\end{abstract}

A infância e adolescência das princesas Isabel e Leopoldina foram marcadas, sem nenhuma dúvida, pelo traço inconfundível da condessa de Barral, não só de forma literal na caligrafia ensaiada à perfeição, como na metáfora de que sua presença era sentida mesmo quando ausente. A ordem, o rigor e as ritualizações prescritas pela condessa davam o tom que regia o cotidiano dos Paços Imperiais de São Cristóvão no inverno e Petrópolis no verão.

\title{
Considerações finais
}

"A viagem para Petrópolis está marcada para o dia 4 de Dezembro por ser um

${ }^{35}$ Carta da condessa de Barral para a princesa Isabel, em 29 de junho de 1863. Arquivo Grão-Pará, Museu Imperial/Abram/MinC. 
Domingo e assim não se perder um dia de estudo". ${ }^{36}$ Com maior influência na formação das princesas do que os próprios pais, Imperadores, ocupados em suas funções cerimoniais, a condessa moldou muitos aspectos da personalidade das meninas, não a sua semelhança, mas tomando como modelo aquilo que ela acreditava ser a exímea educação para mulheres pretensas soberanas de uma nação, seja por meio da contratação dos melhores professores disponíveis no Império, seja com as lições morais cotidianas que impregnavam a atmosfera dos Paços.

Auxiliada por mulheres que não faziam sombra a sua liderança, ela cercou-se de quem confiava e de quem não discutia ou sequer refletia sobre a sua maneira de conduzir a educação das princesas, odedecendo-a em todas as determinações. Esse contexto permitiu que, como nenhuma outra preceptora da família Imperial e, até mesmo, incomparável diante de muitas pares européias, Barral pudesse consolidar sua participação na formação da herdeira do trono do Brasil e de sua irmã, embora esquecendo de ensinar às princesas aquilo que ela mesmo fazia, sua atuação no campo político, tendo em vista a imensa credibilidade que possuía com o Imperador.

A condessa também exerceu grande influência nos casamentos das princesas, segundo Magalhães Júnior (1956), tendo em vista a sua vasta rede de conhecimento e articulação política ${ }^{37}$. A princípio, havia sido pensado o conde d'Eu para a princesa Leopoldina e o duque de Saxe-Coburgo-Gota para a princesa Isabel. No entanto, ao serem apresentados, a princesa Isabel se enamorou do conde d'Eu, enquanto Leopoldina, imaginou-se a futura princesa de Saxe-Coburgo-Gota. Descoberto o interesse pela troca, a condessa participou ativamente da recomposição dos casais, realinhando os casamentos.

Uma semana após o casamento de Isabel, já estava a condessa Ihe enviando uma carta. Mesclando um linguajar trocista numa escrita íntima, ela consegue abordar assuntos de higiene da princesa, descrevendo conselhos de como proceder, como se vestir, como se portar. Ao contar para Isabel que passou o dia arrumando "a seu modo" os cômodos do Paço, ela aparenta um comportamento bem similar ao de uma mãe com uma filha recémcasada, que tenta substituir a ausência sentida nos espaços vazios, pela sensação de proximidade com os pertences palpáveis. Com efeito, por mais admiração e respeito que 0 novo consorte tivesse pela condessa, a proximidade e a influência sob sua esposa não eram vistas com bons olhos pelo jovem recém-casado. Ainda assim, o relacionamento do conde d'Eu com a condessa não gerava maiores conflitos. O mesmo não ocorria com duque de Saxe, marido de Leopoldina. A condessa por se achar incompreendida, dava sinais de insatisfação e ele, por sua vez, agravava a situação ao comportar-se com hostilidade.

Contudo, uma das características mais destacadas de Luiza entre seus pares, sem dúvida, era sua perspicácia e, a partir daí, sua capacidade de lidar com as adversidades. Muitos adjetivos Ihe foram atribuídos para qualificar a capacidade que ela possuía de se antever a determinadas situações e saber lidar com elas, de forma que o resultado the fosse sempre favorável. Foi exatamente esse o motivo que fez a condessa ser reconhecida como uma "mulher politizada", "influente", a frente de seu tempo. Sensível ao clima hostil dos cônjuges das "suas" princesas, uma semana após o envio da carta citada à Isabel ${ }^{38}$, ela

\footnotetext{
${ }^{36}$ Carta da Condessa de Barral para a Imperatriz. Petrópolis, 22 de novembro de 1859. CCCXXXVII - 7 - (1). Arquivo Grão-Pará, Museu Imperial//bram/MinC.

37 Sobre o tema, consultar Saxe-Coburgo e Bragança (2012).

${ }^{38}$ Datada do dia 22 de outubro de 1864.
} 
remete outra, adotando um tom totalmente oposto ao da primeira carta, ou seja, melancólico, na qual pede a Isabel que passe a tomar as próprias decisões. Sugere que ela escolha outra pessoa que the seja de confiança para que lhe aconselhe e pede para que lembre sempre do que aprendeu na infância.

Em reconhecimento pelos relevantes serviços prestados, o Imperador ofereceu à condessa, junto com a pensão vitalícia, o título de condessa da Pedra Branca. Embora a pensão houvesse sido acordada quando nas tratativas em 1856, Luiza achou por bem declinar do valor oferecido, por entender que já havia sido paga por seus serviços. Aceitou, no entanto, o upgrade no título paterno, passando a ser condessa da Pedra Branca.

Embora sendo uma ilusão achar que é possível recompor cenas cotidianas do passado, pois cada uma delas contém inúmeros elementos, cores, linguagens, gestos que, caídos em desuso, escapam a capacidade de recriá-los, as cartas trocadas entre a condessa e as princesas e a condessa e os Imperadores, permitem reviver uma ínfima parte do que se passava no cotidiano dos Paços Imperiais, suficiente apenas para se concluir que a história desses protagonistas seria outra, não fosse sua convivência e aprendizagens recíprocas.

Luiza chegou ao Rio de Janeiro, para ensinar e cuidar da educação de duas meninas de 9 e 10 anos, respectivamente, mas que não se tratavam de quaisquer crianças, eram as herdeiras do trono do Brasil. Oito anos depois, a condessa deixava duas mulheres nobres, casadas, embora continuasse acompanhando, paralelamente, suas vidas e suas histórias. Os laços que haviam sido feitos na infância entre Luiza, Isabel e Leopoldina permaneceriam entrelaçados, ao longo da vida.

\section{Referências}

AGUIAR, Jaqueline Vieira de. Princesas Isabel e Leopoldina: mulheres educadas para governar. Curitiba: Appris, 2015.

ARGON, Maria de Fatima Moraes. A princesa desconhecida. Revista Nossa História, ano 3 , n. 36, out. 2006, p. 74-77.

O mestre de pintura da princesa regente. In: TURAZZI, Maria Inez; ROSSETO, Lourdes (Orgs.). Victor Meirelles: novas leituras. São Paulo: Studio Nobel, 2009.

CUNHA, Maria Teresa Santos. "Por hoje é só..." Cartas entre amigas. In: BASTOS, Maria Helena Camara; CUNHA, Maria Teresa Santos; MIGNOT, Ana Chrystina Venancio.

Destinos das Letras. História, educação e escrita epistolar. Passo Fundo: UPF, 2002.

DEL PRIORI, Mary. Condessa de Barral. A paixão do Imperador. Rio de Janeiro: Objetiva, 2008.

FRANCISCO, Ana Cristina B. López Monteiro. A Condessa preceptora: entre o cotidiano nos Paços Imperiais e a construção do mito. 2017. 319 f. Tese (Doutorado em Educação) - Universidade Católica de Petrópolis, Petrópolis, 2017.

GUEDES, Carmina Correia. A educação dos príncipes no Paço da Ajuda [1863-1884]. Lisboa, 2004.

LACOMBE, Américo Jacobina. Ensaios históricos. Rio de Janeiro: Academia Brasileira de Letras, Comissão de Publicações, 1944.

LYRA, Heitor. História de Dom Pedro II. V. I. Belo Horizonte: Itatiaia, 1977.

MAGALHÃES JUNIOR, Raimundo. D. Pedro Il e a Condessa de Barral. Rio de Janeiro: 
Editora Civilização Brasileira S/A, 1956.

MARIZ, Vasco. Retratos do Império: os Orléans, os Saxe-Coburgo e outras personalidades da época. Rio de Janeiro: Topbooks, 2016.

MATOS, Milton dos Santos. Recôncavo - Berço dos Canaviais. Salvador: Ed. Itapoan, 1976.

MONTEIRO, Mozart. A vida amorosa de D. Pedro II. Rio de Janeiro: O Cruzeiro, 1962. PINHO, Wanderley. Salões e Damas do Segundo Reinado. $3^{a}$ ed. São Paulo: Livraria Martins Editora, 1959.

SAINT-GEORGES. La Contesse de Barral et de Pedra Branca. In: Reveu Mensuelle du Monde Latin. Paris, 1891.

SAXE-COBURGO E BRAGANÇA, D. Carlos. A intriga: retrospecto de intrincados acontecimentos históricos e suas conseqüências no Brasil Imperial. São Paulo: Editora Senac, 2012.

TORRES, Lygia Lemos. Imperatriz Dona Amélia. São Paulo: Elvino Pocaí, 1947.

VASCONCELOS, Maria Celi Chaves. A Casa e os seus Mestres - A educação no Brasil de oitocentos. Rio de Janeiro: Gryphus, 2005.

VASCONCELOS, Maria Celi Chaves; FRANCISCO, Ana Cristina Borges López M. Em busca de uma preceptora para a nobreza brasileira: a Condessa e o Imperador. In: SILVA, Alexandra Lima da; MONTI; Ednardo Monteiro Gonzaga do. Escritas (auto)biográficas e histórias da educação. Curitiba: CRV, 2014.

ANA CRISTINA BORGES LÓPEZ MONTEIRO FRANCISCO é Doutora em Educação pela Universidade Católica de Petrópolis (UCP).

Endereço: Avenida Portugal, 233 - bl. 1/ap. 301, Val Paraíso, 25655-374, Petrópolis/RJ, Brasil.

E-mail: acf@monteirofrancisco.com.br

MARIA CELI CHAVES VASCONCELOS é professora do Programa de Pós-Graduação em Educação da Faculdade de Educação da Universidade do Estado do Rio de Janeiro (Uerj/Proped); Doutora em Educação pela Pontifícia Universidade Católica do Rio de Janeiro (PUC-RJ). Procientista Uerj, Bolsista Produtividade (CNPq) e cientista do Nosso Estado (Faperj).

Endereço: Rua Fonte da Saudade, 240 - ap. 501, Lagoa, 22471-210, Rio de Janeiro/RJ, Brasil. E-mail: maria2.celi@gmail.com

Recebido em 09 de outubro de 2017.

Aceito em 20 de fevereiro de 2018. 